\title{
Redesenho da interface digital da revista arco: o design centrado no usuário com a utilização do método 5 I's
}

Redesign of digital interface of arco magazine: user centered design with the method of 5 l's

Juliana Krupahtz ${ }^{1}$

Débora Aita Gasparetto ${ }^{2}$ 


\section{Resumo}

Este artigo tem o objetivo de expor e analisar o método de desenvolvimento de interfaces centrado no usuário, a partir do redesenho do site da Revista Arco da Universidade Federal de Santa Maria (UFSM). A metodologia de projeto tem sido utilizada no Laboratório de Interfaces do Desenho Industrial da mesma instituição e mescla etapas propostas pelos autores [GARRET, 2011] e [LOWDERMILK, 2013]. Como resultado, pretende-se compartilhar um método eficiente para projetar adequadas experiências de usuário nas interfaces digitais. A proposta inclui pensar em pontos de interação entre a interface do website oficial da revista e projetos interativos que encaminhem o usuário à experiência completa que a revista oferece.

Palavras-chave: experiência de usuário; design de interface; redesenho

\section{Abstract}

This article's objective is to expose and analyze the method of user centered interface development from the redesign of Arco magazine's website that belongs to Federal University of Santa Maria (UFSM). The project methodology has been used at the Interfaces Laboratory of Industrial Design, from the same institution, and merges the steps proposed by the authors [GARRET, 2011] and [LOWDERMILK, 2013]. As a result, it is intended to share an efficient method to project appropriate user experiences on digital interfaces. The proposal includes thinking in interaction points between the interface of the journal official website and interactive projects that guide the user to a complete experience already offered by the journal.

Key-words: user experience; interface design; redesign 


\section{Introdução}

O design centrado no usuário tem ganhado espaço nas principais discussões sobre as interfaces digitais. No entanto, a pergunta que surge é se todo o design não deve ser centrado no usuário. Pensando no projetista como um resolutor de problemas reais, um facilitador de experiências entre o usuário e o mundo, seja ele digital ou analógico, a resposta é sim, todo o design deve ser centrado no usuário. Todavia, centrar o projeto no usuário significa incluí-lo no processo de desenvolvimento de interfaces, abrir espaço para que não apenas o cliente e o projetista decidam os caminhos que irão oferecer.

Conforme Lowdermilk (2013) o design centrado no usuário é uma metodologia que deriva da Interação Humano-Computador (IHC) e tem foco na experiência de usuário, por isso analisa o que o usuário precisa, o contexto de uso de determinado dispositivo e o próprio comportamento humano.

Como o webdesign está focado na experiência do usuário, diversos autores irão abordar a User Experience. No Brasil, Fabricio Teixeira (2014), reúne alguns princípios sobre User Experience (UX). Conforme ele os UX designers são responsáveis por definir como as pessoas irão interagir com o produto, é este profissional que desenha a estrutura dos produtos digitais. A UX é muito mais ampla que 0 , mas também é aplicada a ele. Conforme ele a UX envolve as áreas de arquitetura de informação, usabilidade, design de interação, taxonomia, estratégia de design e pesquisa com usuários.

Esse artigo aborda as dificuldades e as oportunidades que se abrem quando o usuário é incluído no projeto, quando se utiliza pesquisa e cruzamento de dados reais para aprimorar o desenvolvimento de cada etapa da projetação. Para iniciar essas análises, é fundamental contextualizar o projeto de Redesenho do website da Revista Arco, desenvolvida em conjunto com o Laboratório de Experimentação em Jornalismo (LEx) e o Laboratório de Interfaces do Desenho Industrial da UFSM, no qual o projeto foi desenvolvido.

O LEx é um laboratório do Curso de Comunicação Social - Jornalismo (UFSM) e concentra suas atividades na produção jornalística na era das mídias digitais, além de também participar da produção da Revista Arco - veículo da Coordenadoria de Comunicação Social da Universidade - de jornalismo científico e cultural impresso e digital. A Arco é a revista institucional da UFSM produzida por técnico-administrativos, alunos do curso de Comunicação Social - Jornalismo e uma docente, no LEx. O material elaborado é divulgado pelo site da revista, no endereço http://ufsm.br/arco. Essa revista, que circula on e off-line, é o projeto que pauta o presente artigo, pois seu site não atendia mais os requisitos e funcionalidades exigidos pela equipe de produção. Assim, o foco é a Arco Digital (Figura 01), mesmo que pontos de contato com a Arco Impressa tenham sido estrategicamente propostos. 


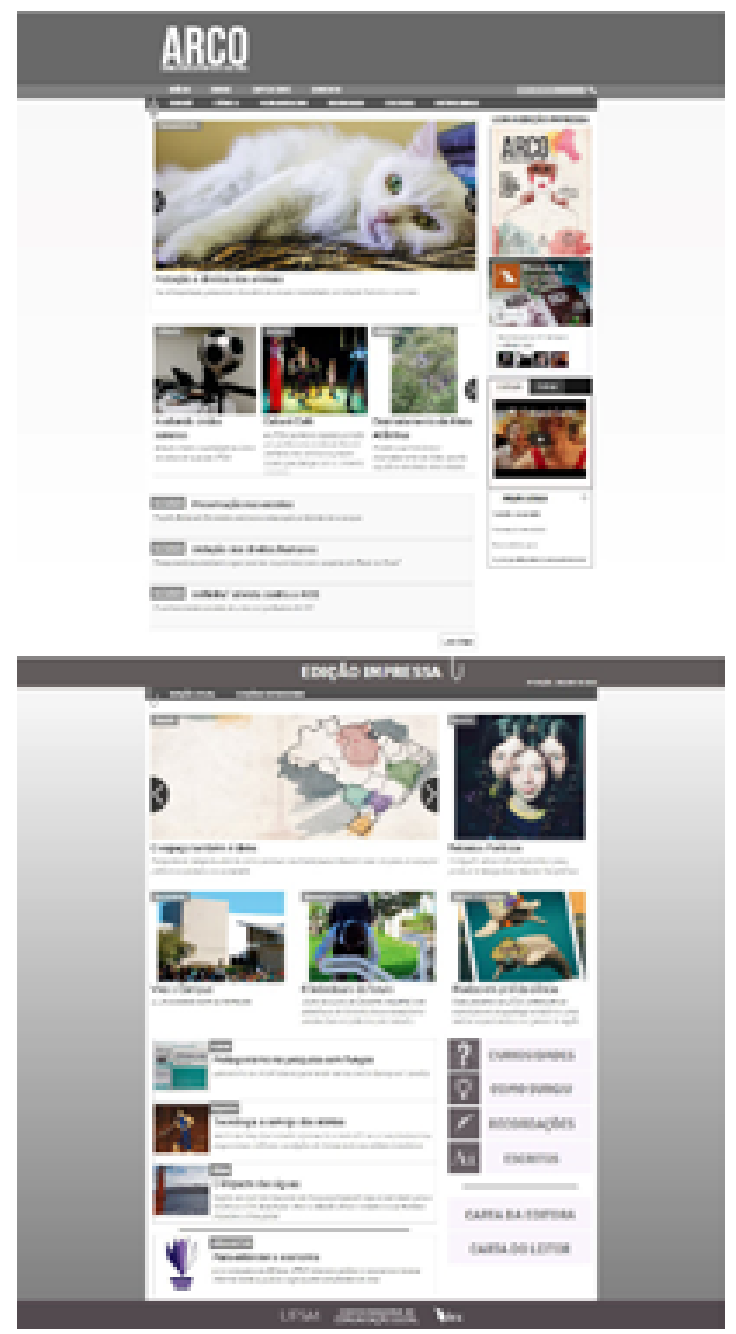

Figura 1: Captura de Tela Website da Revista Arco Digital, antes do redesenho. Fonte: http://ufsm.br/arco

O Curso de Desenho Industrial da UFSM tem uma nova estratégia curricular, com foco na relação mestre-aprendiz, por meio de trocas entre alunos dos Laboratórios Profissionalizante e Orientado, sob coordenação dos professores responsáveis. Nesse contexto, no segundo semestre de 2016, o Laboratório de Interfaces teve como proposta projetar interfaces digitais partindo de problemas reais e de clientes reais, mas pensando para além da usabilidade, acessibilidade e aspectos tecnológicos dos websites, nas novas possibilidades de experiência de usuário abertas pela realidade aumentada e virtual. É importante mencionar que todos os alunos participantes do laboratório estão envolvidos semanalmente em discussões sobre os projetos, participando de dinâmicas de testes. Isso, de fato, foi extremamente importante para o Projeto da Revista Arco, pelo fato de que os alunos também fazem parte do público-alvo da Revista.

$O$ encontro dos dois laboratórios, LEx e de Interface, permitiu que necessidades reais proporcionassem aprendizado e unificassem o trabalho da bolsista e autora, tornando-o interdisciplinar. A interdisciplinaridade é sempre recorrente em projetos digitais, pois os mesmos envolvem conhecimentos desenhísticos, artísticos, ergonômicos e de programação, ao menos, de FrontEnd. Profissionais, cada vez mais, híbridos ganham destaque no mercado de webdesign. Porém, nessa oportunidade, a área de Comunicação Social ofereceu um suporte para que estratégias de ponto de contato com 
o website da revista fossem melhor desenvolvidas, em um projeto que, normalmente, não pensa para além da página que projeta. É importante destacar que essa proposta interdisciplinar também contou com a participação do bolsista Guilherme Bastos, do curso de Ciência da Computação.

A responsável pelo LEx, Prof. ${ }^{-}$Dra. Laura Storch, e a editora-chefe da revista Arco, a jornalista Luciane Treulieb, clientes deste projeto, foram peças-chave, estando sempre presentes durante o processo criativo para o redesenho da nova interface do site da revista, que foi desenvolvida no Laboratório Profissionalizante de Interface, com a orientação de uma das autoras.

Como em todo projeto de design, o briefing foi o ponto de partida. Ainda em uma primeira reunião com as clientes, foi pautada uma divisão para a exibição das matérias da Arco Digital e Arco Impressa, tendo as publicações organizadas por ordem cronológica na página principal. Em acesso às informações proporcionadas pelo Google Analytics, em relação à edição da revista percebeu-se o número muito baixo de acesso à seção do site destinada à revista impressa, localizada na metade inferior da página principal, por isso foi requisitado também um destaque melhor estruturado a essa divisão do site. Ainda na homepage, também deveria ser organizado o leiaute com espaço para matéria destaque, porém que não ocupasse o espaço de uma lateral da tela a outra, pois acabava prejudicando as fotografias utilizadas, que são produzidas pela própria equipe do LEx. Um processo criativo com participação tanto do usuário que irá produzir o conteúdo para a interface - usuário publicador - quanto do usuário que irá consumir a informação ali publicada - usuário leitor -, faz com que o projeto se torne muito mais eficiente nos seus resultados. Tanto na aplicação de pesquisa com usuário, no estudo das personas como no contato direto com o público-alvo da revista (professores, alunos e membros da comunidade da UFSM), percebeu-se que a interface do website antigo da revista dizia respeito a um espaço-tempo anterior, necessitando uma adaptação de linguagem para que mais pessoas do seu público-alvo tivessem acesso a ela. Diversas alterações foram feitas conforme as considerações de todas as partes envolvidas no processo de projetação com foco no usuário. A seguir descreve-se a metodologia utilizada, elaborada por uma das autoras, com base nas fases sugeridas pelos autores Jesse James Garret (2011) e Travis Lowdermilk (2013). A metodologia dos 5ls, publicada em primeira mão no presente artigo, é baseada na ação, envolve as seguintes fases: ideação, incubação, implementação, inspeção e instauração.

\section{Considerações sobre a metodologia}

Trabalhar com design centrado no usuário em Interfaces digitais significa basear o projeto na experiência que se quer oferecer ao usuário. Para isso é imprescindível recorrer a referências chaves como Garret (2011). O autor propõe um método simples de projetar que pode ser aplicado desde até projetos interativos mais complexos, para web e além, método esse baseado na experiência de usuário e subdividido em 5 grandes etapas (Figura 02), que vão de um nível mais abstrato e mais próximo do designer até um mais concreto, que está mais próximo do usuário. A proposta divide o 
produto em funcionalidade e informação, ambas ocorrendo concomitantemente em cada etapa.

$\mathrm{Na}$ etapa preliminar, representada pela Estratégia, busca-se um diálogo projetual entre o que o usuário precisa e o que o produto objetiva. A próxima etapa, Escopo, traz as especificações funcionais e os requisitos de conteúdo da interface. Após resolvê-los, é planejada a Estrutura do projeto, com a arquitetura de Informação e o design de Interação. Na sequência vem o Esqueleto, com o Design de Interface, o Design de Navegação e também de Informação. A última etapa, na Superfície e já mais perto do usuário, há o Design Sensorial. Esse na primeira publicação de Garret (2003) era considerado como Design Visual, no entanto, as interfaces sonoras, táteis, as Natural User Interface (NUls), que estimulam e são acionadas por meio de outros sentidos, e com a emergência da internet das coisas, o termo sensorial ficou mais adequado.

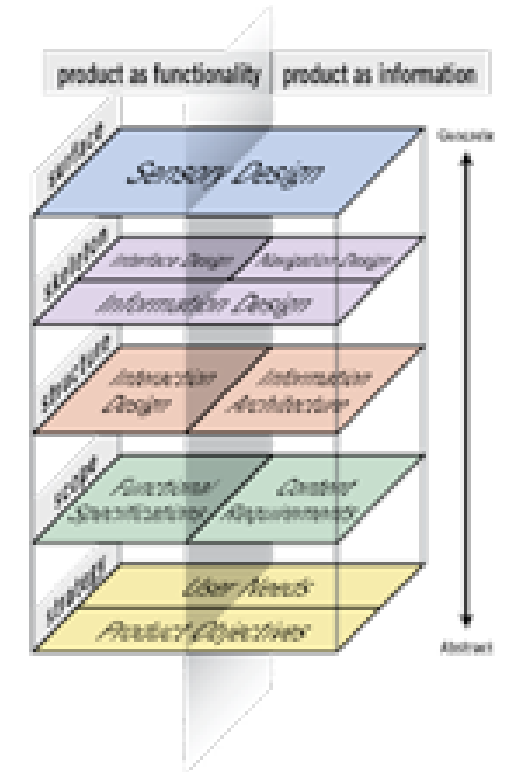

Figura 2: Esquema visual da metodologia proposta por [Garret, 2011]

Embora a metodologia sugerida por Garret seja bastante pertinente, cada projetista, adapta-se melhor ou pior a uma metodologia. Com a emergência de ferramentas de prototipagem interativas como UxPin, Proto lo, JustInMind, entre várias outras em um campo crescente de ferramentas, essa divisão mais delimitada pode ser ainda mais simplificada, agrupando etapas de estrutura e esqueleto, por exemplo. Ainda inserir testes com usuário a cada etapa e inseri-lo na projetação da interface, ouvindo suas críticas e considerações, pode eliminar erros e ajustar a interface a um padrão de pensamento que é diferente do padrão do designer ou do cliente. É importante mencionar que pesquisa recente do Nielsen Group [NIELSEN, 2016] demonstrou que apenas $5 \%$ da população de 33 países ricos se considera avançada em informática. Isso demonstra como a própria pesquisa sugere, que o designer ou programador não é o usuário. Assim coisas que parecem óbvias para os avançados, não são tão óbvias assim para 95\% da população.

É por isso que o Design Centrado no Usuário de Lowdermilk (2013) pode contribuir para a elaboração de uma metodologia que não inclui apenas pesquisas e 
desenvolvimento de personas, mas também um usuário acompanhando as etapas. Embora a publicação desse referido autor seja bastante facilitada ao público leigo, traz preciosas dicas para quem está iniciando o desenvolvimento de interfaces, sobretudo de aplicativos. "O processo de design centrado no usuário funciona contra pressupostos subjetivos acerca do comportamento dos usuários. Ele exige provas de que suas decisões de design são eficazes" [LOWDERMILK, 2013, p. 27]. Assim aceitar feedbacks, compreender fluxos e tarefas de um padrão mental do usuário fazem parte desse método.

Visando unir as questões mais focadas no usuário e nas personas de Lowdermilk, com as etapas muito bem documentadas de Garret, o método 5ls propõe ser um facilitador ao projetista iniciante, de fácil assimilação pelas " 5 " etapas que iniciam com a letra "i", focadas no sujeito eu "I", mas que no plural "s" significará nós. Essa ação conjunta entre projetistas, clientes e usuários torna a projetação compartilhada e mais eficiente, no sentido de minimizar erros. As etapas dividem-se do seguinte modo: 1) IdeAção - fase que inclui o briefing, que é realizado e explorado; o brainstorming, a tempestade cerebral das boas e más ideias; uma busca inicial por referências na área para não casar com uma ideia que já existe ou para aprimorar uma ideia mal elaborada; a elaboração de mapas mentais com as ideias-chaves do projeto; as primeiras pesquisas com usuário para verificar questões que o briefing possa ter deixado em aberto; elaboração de personas, a partir dos resultados dessas pesquisas, mas também da análise do público-alvo em contextos de uso e ainda pontos de contato, que levam a criar situações de encontro entre o usuário e o projeto de interface digital. Nessa fase é primordial que o projetista se aproxime de campos como psicologia cognitiva e, sobretudo, neurociência, porque tudo é sobre experiência.

A etapa 2 é a da IncubAção, aqui busca-se compreender as personas criadas para extrair os requisitos e funcionalidades, os primeiros voltados às necessidades do usuário e os segundos ao detalhamento técnico da interface. Ainda nessa fase realiza-se uma pesquisa mais profunda com análise de referências, que podem ser tanto de interfaces concorrentes, quanto de interfaces que dispõem de requisitos e parâmetros que o projeto tem como base. Aqui levantam-se os prós e contras. Nessa fase escolhe-se também as tecnologias a serem utilizadas para a implementação do projeto.

Na etapa 3, a da ImplementAção, realizam-se rabiscoframes [Teixeira, 2014], o sitemap, o cardsorting, os protótipos em papel e interativos, organizando a arquitetura de informação e design de interação. Aqui é fundamental a participação do usuário no processo de rotulagem e arquitetura de informação, deixando o projeto adequado as suas necessidades. Simultaneamente, nessa etapa é pensado o design sensorial, que é refinado na etapa seguinte. Assim, conhecimentos do campo do design, como simetria, harmonia, proporção, uso de grids, forma/função, trabalho de ícones, fontes, imagens, vídeos e sons já são previamente escolhidos nessa etapa e refinados ou atualizados mais tarde.

A 4⿳亠口冋 etapa traz a Inspeção, aqui o refinamento é realizado após serem implementados testes de usabilidade e acessibilidade com usuários, aqui se faz análise detalhada da interface e se verificam as heurísticas de avaliação. É importante inspecio- 
nar se além de agradável visualmente e sensorialmente, o projeto está consistente, se gera feedbacks adequados, se previne erros, se segue padrões, entre outros itens que normalmente são avaliados, no contexto do Laboratório com base em Jackob Nielsen. Essas etapas valem para todos os formatos de responsividade, ou seja, capacidade do projeto de se adaptar a diferentes formatos de tela, sobretudo quando falamos de web.

Por fim, parte-se para a InstaurAção, momento em que se executa e entrega do produto final e são realizadas novas inspeções e substituições, caso sejam necessárias. Como afirma Lowdermilk (2013), um projeto de interface digital nunca está pronto. Isso acontece porque diferentemente de edições impressas, a atualização dos meios digitais é dinâmica, pode-se observar erros e prontamente corrigi-los sem custos onerosos. Ainda é importante mencionar que a linguagem digital se atualiza constantemente, forçando as interfaces a ajustarem-se às novas tendências, com risco de ficarem obsoletas ou datadas.

Outro ponto importante de se destacar em relação à metodologia dos 5ls é a abertura para trabalhar em sintonia com outras metodologias, como o Documentos de Game Design (GDD), Roteiros para vídeos hipermídia ou ainda social media. Isso porque a base dela é semelhante a qualquer outro método de design, uma das poucas diferenças é a discussão de cada etapa não apenas com o cliente, mas também com o usuário, focando na sua experiência e buscando resolver os seus problemas. Ainda a proposta é flexível permitindo ao projetista a supressão de algumas etapas, como wireframes estáticos em Illustrator, por exemplo, ou das personas, quando se trabalha com um usuário real em todo o projeto.

Porém, no contexto contemporâneo em que a pressa acaba suprimindo etapas e a voracidade do mercado inibe pesquisas mais aprofundadas, essa metodologia centrada no usuário pode parecer impraticável, pelo tempo que dispende nas etapas que antecedem o projeto visual e sensorial. No entanto, toda a pesquisa anterior quando bem empregada e a possibilidade de trabalhar com o público, diretamente, previne erros e refações. Quando se fala em inserir o usuário no processo, pode-se simplificar o caminho até ele, escolhendo pessoas próximas da persona criada, como filhos, pais, mães, amigos. Pessoas diferentes que tenham pontos em comum com o público-alvo da interface são melhores do que não testar com ninguém.

\section{Aplicação da metodologia 5 Is no redesenho do website da revista arco}

Durante o processo de construção do briefing com o cliente foi estruturado quais eram os problemas identificados na interface digital anterior ao redesenho, tanto estéticos quanto de funcionamento, como recursos limitados em termos de programação. Dentre esta lista de requisitos estavam: (i) destaque para a edição da revista impressa, com a capa da revista aparecendo na página inicial; (ii) melhor divulgação das redes sociais institucionais da Revista Arco; (iii) maior destaque às fotografias, como já mencionado; (iv) comentários vinculados às redes sociais; (v) publicações relacionadas no final do texto da matéria da revista; (vi) serviço de publicação com mais recursos e melhor controle do banco de dados; (vii) paleta cromática mais 
dinâmica e atendendo melhor ao público-alvo da Revista - que será melhor estudado na próxima etapa; (viii) pontos de contato com o usuário mais direto e em diálogo com o perfil desse público.

\subsection{Big Ideação e Incubação: buscando o perfil do usuário e o contexto de} uso

Conforme a metodologia utilizada, foi realizada uma pesquisa online, via Google Forms, para sintetizar o perfil do usuário da interface e poder definir quais os requisitos e funcionalidades exigidos para cada persona. Foram feitas 25 perguntas rápidas, direcionadas conforme as respostas dos respondentes, com uma abordagem de 52 pessoas, em 13 dias. O formulário foi divulgado pelo sistema de comunicação via e-mail da UFSM, ou seja, enviado para todos os e-mails cadastrados no sistema da universidade, entre servidores, professores e alunos. Apesar do número não muito alto de respostas, os resultados foram significativos para determinar o público interessado em colaborar para o desenvolvimento da revista e, consequentemente, mais interessado em seu conteúdo.

A construção do questionário foi dividida em (i) perfil do usuário: faixa etária, nível de escolaridade, vínculo com a UFSM, ocupação e se possuía deficiência física ou intelectual; (ii) consumo de informação: qual o instrumento utilizado para acessar a internet e quais meios de comunicação utilizados para isso (sites de revistas e jornais, edições impressas, blogs, vídeos na internet, televisão e redes sociais); (iii) vínculo com a Revista Arco: se já conhecia a Revista, se já havia conhecido a edição impressa, se já havia acessado o website da Revista, preferência entre versão impressa e digital, como acessava o website (mecanismo de busca, links direcionados ou pela página institucional da Universidade) e qual setor do site era o mais frequentado; por fim (iv) as tecnologias utilizadas: uso de aplicativos, se possuía aplicativos específicos para notícias e se já havia tido experiências com realidades aumentada e virtual. Essas três últimas perguntas foram feitas pensando em projetos futuros que possam ser realizados junto à Revista, como o desenvolvimento de um aplicativo para armazenamento das edições impressas, e projetos de realidade aumentada e realidade virtual.

Dos resultados obtidos, 57,1\% dos respondentes tinham entre 18 e 25 anos e 49\% eram estudantes de graduação. Na seção sobre o consumo de informação, 91,8\% disse acessar por sites de revistas e/ou jornais, enquanto a opção "Links direcionados a partir de redes sociais" teve $86,5 \%$ de taxa de resposta, ficando como segunda opção mais selecionada. A partir da associação apenas dessa única pergunta, é possível entender a forma de navegação na web do público-alvo, considerando, ainda, os altos números de acesso em matérias divulgadas na página inicial do site institucional da UFSM, mas que não revertiam em acesso a outras páginas do site da revista, ou seja, o usuário visita o site com o propósito de ler aquela única publicação, e fecha logo que conclui a leitura da matéria.

A partir da pesquisa direta com o usuário foi traçado o perfil de três personas, chamadas de (i) Diego, (ii) Samanta e (iii) Gabriela. Diego tem o perfil de estudante de graduação da Universidade, acadêmico do curso de Psicologia, com 21 anos. Ele cultiva o hábito da leitura e já tem contato com a revista Arco na versão impressa, que se 
destaca entre os alunos do campus por ter um bom projeto editorial. A partir da análise específica dessa persona, é possível definir como requisitos particulares: (i) a necessidade de uma interface objetiva, (ii) boa leiturabilidade e legibilidade, (iii) acesso por múltiplas telas, para que o site conquiste leitores que gostam de ler no papel, e uma consequente (iv) coerência estética com a versão impressa. Quanto às funcionalidades associadas seriam (i) poucos caminhos para se fazer uma tarefa, (ii) vínculo mais eficaz com as redes sociais e um (iii) bom contraste entre texto e imagem.

Samanta, a segunda persona criada, também é acadêmica da Universidade, porém do curso de Publicidade e Propaganda, está sempre atualizada com as últimas tecnologias lançadas no mercado. Ela não conhece a revista Arco impressa e somente teve contato com algumas matérias do site, vinculadas com as suas redes sociais. Os requisitos da Samanta são: (i) um bom planejamento estético, (ii) interface mais atemporal, (iii) leiaute minimalista, (iv) chamadas de publicações atraentes com textos curtos como descrição. Das funcionalidades, destacam-se as de (i) notícias em destaque na página principal, (ii) matérias relacionadas no final da página, logo abaixo do texto principal, (iii) menus interativos e (iv) responsividade.

A terceira e última persona, Gabriela, tem 34 anos e é professora da Universidade, do curso de Medicina Veterinária. Ela está começando a se atualizar em relação às tecnologias, vai de bicicleta para o trabalho e cresceu em uma cidade do interior, nas redondezas de Santa Maria. Para Gabriela, é importante se manter informada sobre as notícias relacionadas à UFSM e ao seu departamento, por isso conheceu a revista Arco ao clicar em um link no site institucional da universidade, e gostaria de poder sugerir pautas para matérias futuras. Ela irá requerer (i) matérias de cunho acadêmico, (ii) expediente da equipe da revista, para entrar em contato e um (iii) leiaute objetivo. Nas funcionalidades, destaca-se a importância de (i) uma barra de pesquisa bem localizada, (ii) o uso de tags nas matérias, para facilitar a pesquisa do usuário, (iii) página com formulário e informações de contato e (iv) um mapa do site.

Essas três personas resumem a maior parte do diverso público que acessa tanto a Arco Digital quando a Impressa. Todavia, ele ainda é composto por uma parcela de servidores da universidade, professores, e também da população da cidade. Durante o briefing, as clientes expuseram um projeto de extensão - mesmo não sendo o foco da Revista, que é de cunho científico e cultural - com as escolas públicas de Santa Maria, e a vontade de mostrar mais da Universidade Federal para esses alunos que estavam tendo contato com as matérias da Revista. Com essa informação, foi iniciada a estrutura de um projeto de realidade aumentada, com planos de ser implementado futuramente, que mapeasse o espaço físico do campus, marcando pontos relacionados às matérias já publicadas pela revista. Além disso, um aplicativo para servir como suporte a esta plataforma, com espaço para agendamento de visitas ao campus por turmas das escolas já mencionadas. Devido à necessidade prioritária das clientes ser a implementação do site, este projeto foi deixado para ser finalizado após a conclusão dessa etapa.

Após a definição das categorias de usuário que estariam no centro do projeto, foi feita uma busca por sites da mesma categoria e listados os elementos possíveis de serem usados como referência, para atender os requisitos e funcionalidades listados acima. Entre eles estão os sites da revista Piauí, pertencente à Folha de São Paulo, da 
revista Super Interessante, da editora Abril, e da Port Magazine, que se destacou pelo leiaute minimalista, pouco uso de cores e relevância da tipografia (Figura 03).

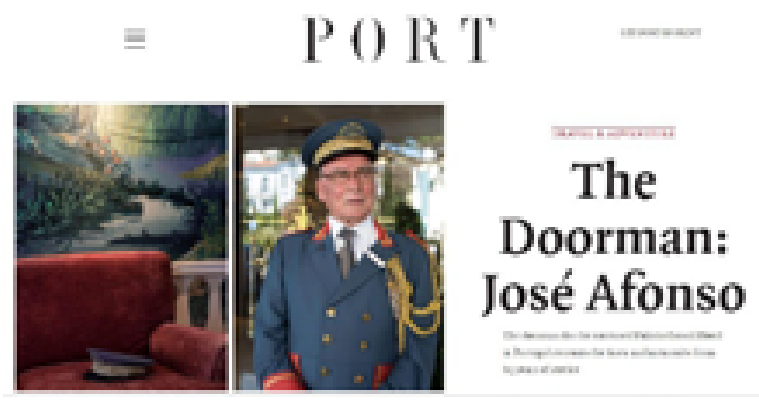

Figura 3: Página inicial com destaque à matéria principal da revista Port. Fonte: http://www.port-magazine.com

\subsection{Implementação - primeira geração de alternativas}

Nesta etapa, onde foi iniciada a concepção gráfica, com o recurso de rabiscoframes (Figura 04) e card sorting, é importante destacar que devido à importância da responsividade e acesso por múltiplas telas do website, foi associado o método Mobile First (Figura 05) para o planejamento das telas [WROBLEWSKI, 2011]. Esse método se popularizou após Wroblewski ter escrito, em 2009, que normalmente se pensa no design para os dispositivos móveis depois de se pensar no webdesign para desktop. Ele vai propor inverter essa relação, pois há uma explosão da tecnologia mobile, o design para mobile exclui elementos desnecessários e os dispositivos móveis trazem novas funcionalidades de uso. Wroblewski argumenta que pensar primeiro na versão mobile significa inovar por meio de possibilidades que não existiam antes das mídias móveis. O referido autor sugere que se inicie pela menor tela, pois se as informações couberem nela, logo se adaptarão bem a todas as demais telas. Isso ajuda a simplificar os projetos.

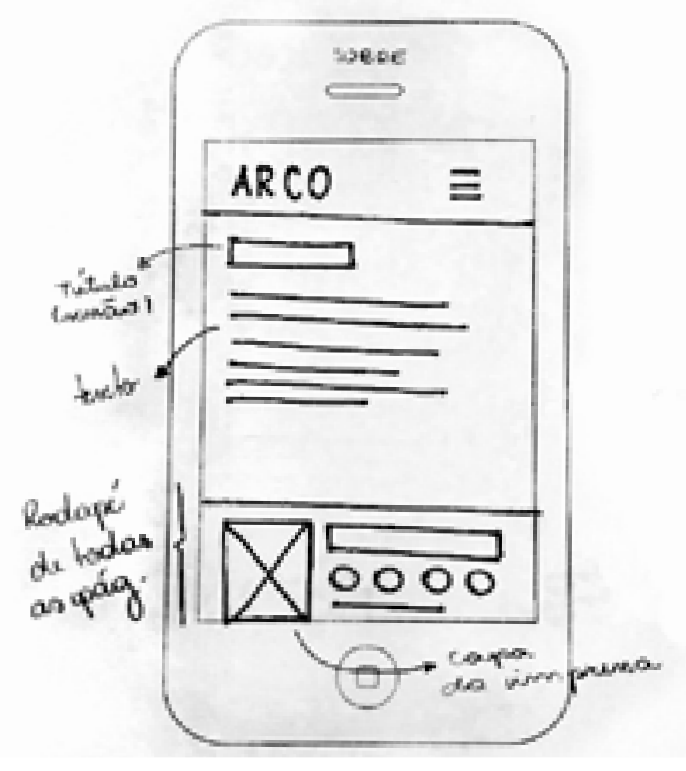

Figura 4: Rabiscoframes. Fonte: Desenvolvido pela autora 


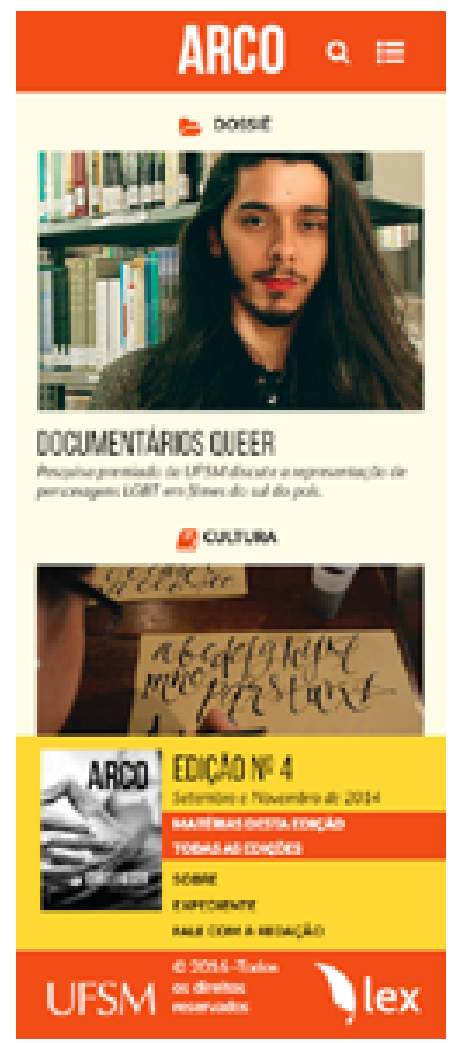

Figura 5: Geração de Alternativas leiaute Mobile. Fonte: Desenvolvido pela autora

Para o desenvolvimento do protótipo, tanto na versão mobile quanto na versão desktop (Figura 06), foi utilizado o programa Adobe Muse na versão CC 2015. Devido a sua interface voltada aos profissionais da área criativa, sendo bastante visual e intuitivo, o processo acabou sendo facilitado, por ter poucas etapas envolvendo programação. Contudo, algumas dificuldades foram encontradas, como na (i) configuração do menu na versão mobile, (ii) interações com as redes sociais, (iii) configuração da barra de pesquisa, (iv) o fato do código HTML gerado pelo software não poder ter aproveitamento adequado na parte de implementação, por trazer bibliotecas próprias que não são padronizadas e (v) não oferece programação de BackEnd de modo intuitivo como faz com FrontEnd, exigindo a presença de um programador.

\subsection{Inspeção: as rodadas de testes com usuários}

No contexto do Laboratório de Interface e também do LEx, semanalmente foram realizados testes com os usuários-publicadores (profissionais e alunos vinculados à Arco e ao Lex que são responsáveis pela produção que abastece o banco de dados do site e participam diretamente do processo de construção da Revista Digital) e também com os usuários-leitores (alunos do Laboratório de Interface e professores, ambos parte do público da Revista). Nestes testes, inicialmente era apresentada a interface superficialmente, para que dessem opiniões sobre estética e estrutura, e logo após também eram destinadas tarefas para que uma pessoa cumprisse, como: acessar uma matéria específica, ou entrar em contato com a Revista. Então se observava a interação do usuário com a interface para que o caminho escolhido por ele 
fosse no final o caminho com o menor número de cliques e menor tempo.

Estes testes auxiliaram na simplificação da interface e na implementação da UX, além de levantarem problemas com a paleta de cores inicialmente pensada para o projeto, bem como a hierarquização das informações de menu e a padronização dos ícones. Juntamente com os testes feitos pelos usuários da revista e a análise das clientes foi realizada a decisão editorial de remover duas das seis editorias da revista, para que o menu não ficasse tão poluído e impreciso aos leitores.

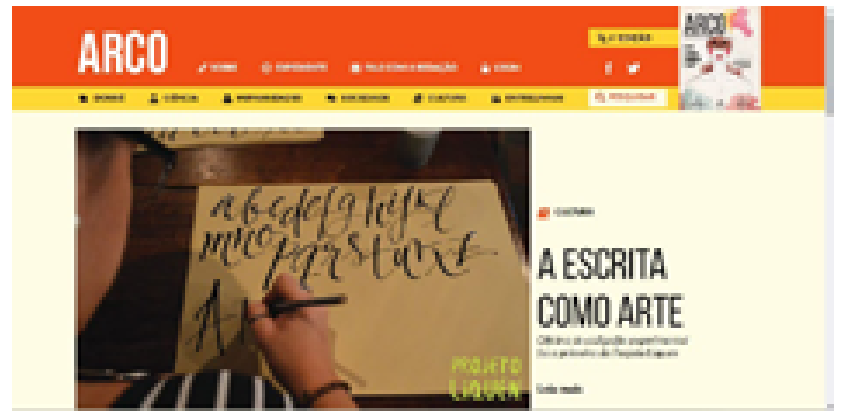

Figura 6: Geração de Alternativas versão Desktop. Fonte: Desenvolvido pela autora

É importante destacar que em um primeiro momento, se trabalhou com uma paleta cromática com cores bastante saturadas, porém incluindo o laranja, que já estava presente na versão do site anterior. Conforme os testes feitos com os usuários na parte de leitura de texto, percebeu-se que essas cores acabavam prejudicando a leitura e consequentemente fazendo com que o usuário saísse do site mais rapidamente, sem capturar a experiência que se intuía oferecer a ele.

\subsection{Implementação: escolhendo cores, ícones, fontes e grids}

$\mathrm{Na}$ etapa de Implementação, partiu-se para as mudanças propostas tanto por parte das clientes, quanto pelos resultados dos testes feitos com os usuários. A primeira mudança foi feita na paleta cromática (Figura 07), como já mencionado, onde optou-se pelo uso de cores menos saturadas e frias, tendo apenas uma cor quente para os detalhes, o tom de laranja que já acompanhava a interface anterior, utilizadas nas tags e em alguns pontos específicos. O grid foi organizado para um melhor aproveitamento do maior número de telas, já que o site anterior desperdiçava muita área branca sem conteúdo, por isso foi escolhida a largura de tela de 1140px e divisão em 14 colunas, para um melhor alinhamento de todo o conteúdo (Figura 08).

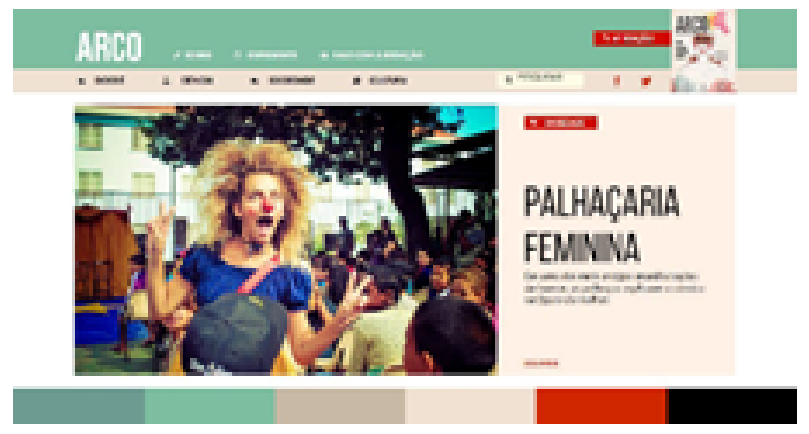

Figura 7: Tela da versão final do site com paleta cromática de referência na parte inferior. Fonte: Desenvolvido pela autora 
No início do projeto, as clientes apresentaram o Guia de Estilo da Revista, já existente, para auxílio na preservação da identidade visual. Por este motivo, a família tipográfica escolhida para os títulos foi a mesma já utilizada na edição impressa, a Bebas Neue, de Ryoichi Tsunekawa, livre para uso comercial tanto de webfont quanto versão desktop. Para fonte de texto foi escolhida a Lato, desenhada por Łukasz Dziedzic, gratuita, livre para uso comercial, com cinco pesos disponíveis, inclusos os itálicos, além de ter boa legibilidade e leiturabilidade. Para acompanhar o desenho da tipografia de texto, foi definida uma biblioteca de ícones com traços arredondados e visual minimalista (Figura 09).

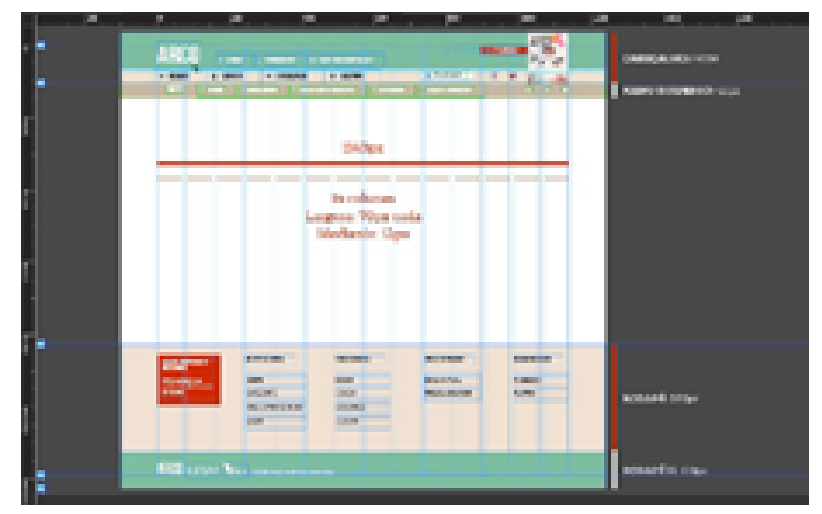

Figura 8: Grid utilizado para composição do site. Fonte: Desenvolvido pela autora

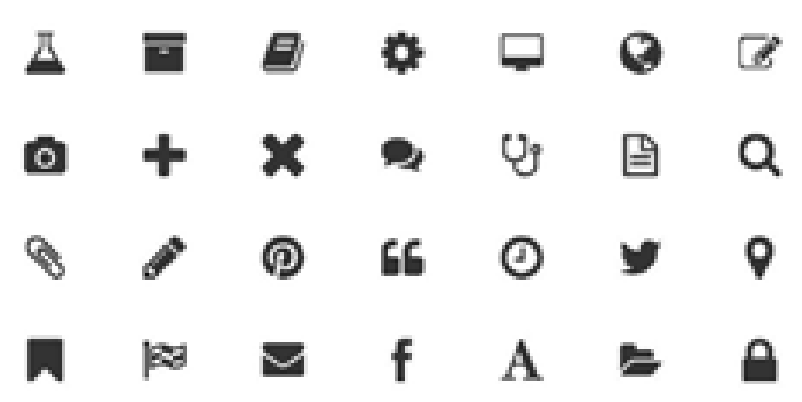

Figura 9: Biblioteca de ícones utilizada. Fonte: Desenvolvido pela autora

\subsection{A instauração da nova Arco Digital}

O protótipo interativo do website (Figura 10) foi realizado com o uso da ferramenta Adobe Muse, já mencionada, que exporta em HTML 5, CSS3 e JavaScript. No entanto, a programação de BackEnd permite a replicabilidade de conteúdo, a facilidade de abastecimento e gerenciamento para o cliente. O projeto de programação foi implementado pela empresa júnior de Tecnologia da Informação, CompAct Jr., que engloba os cursos de Ciência da Computação, Engenharia de Computação, Sistemas para Internet, Sistemas de Informação e Tecnologia em Redes de Computadores, do Centro de Tecnologia e do Colégio Politécnico da UFSM.

Para um melhor entendimento de como foi feito o projeto gráfico, foi elaborado um material auxiliar a ser utilizado como manual de estilo durante o projeto de programação. Como conteúdo expõe-se as referências de cores (Figura 07), grids (Figura 
08), ícones (Figura 09) e também os estilos tipográficos utilizados (Figura 11).

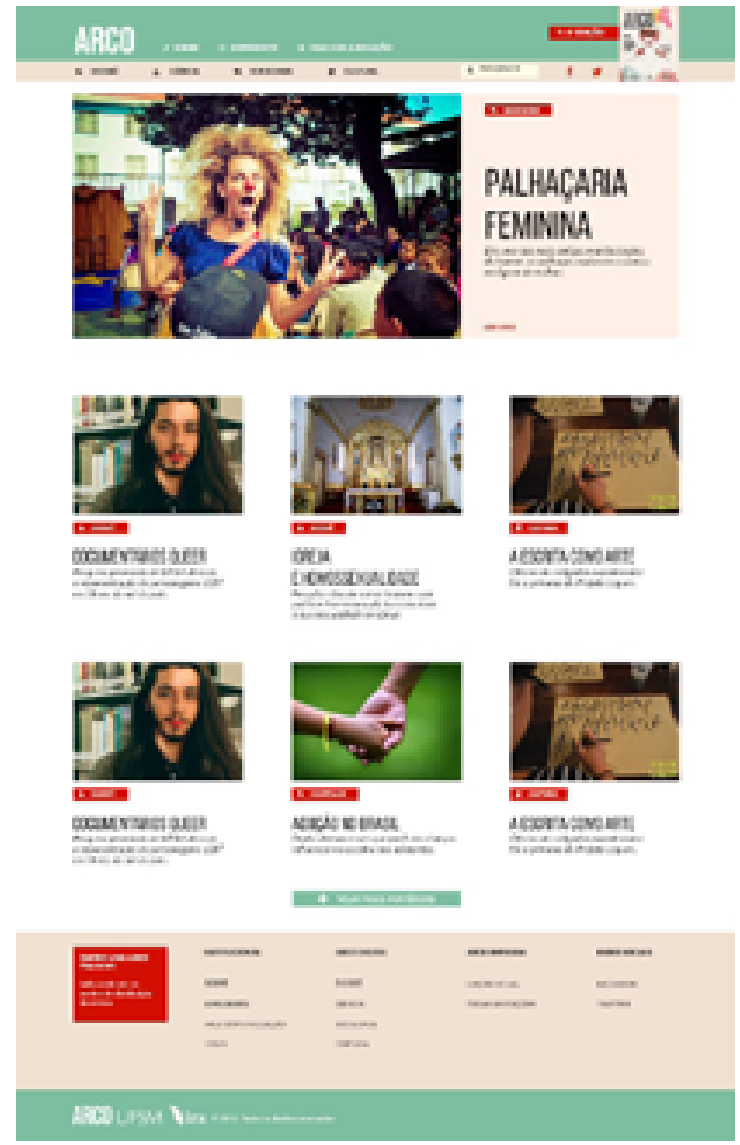

Figura 10: Tela da página inicial da versão final do protótipo. Fonte: Desenvolvido pela autora

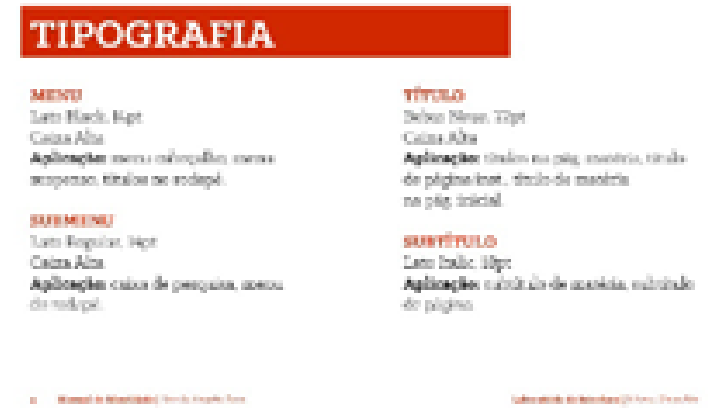

Figura 11: Página do manual referente aos estilos tipográficos utilizados. Fonte: Desenvolvido pela autora

Este material foi disponibilizado no início da programação do novo site e acabou facilitando muito o processo de comunicação entre designer e programadores, para que o produto final se mantivesse visualmente fiel ao protótipo.

Esta fase consistiu em reuniões semanais com a equipe da empresa júnior, a autora e uma amostra dos usuários-publicadores, e uma das maiores dificuldades encontradas foi a adaptação do leiaute. Algumas margens e objetos da interface tiveram que sofrer reajuste de tamanho por limitações da programação, o que poderia ter sido evitado ao ter um acompanhamento mais próximo de um profissional da área no processo de criação gráfica, ou até mesmo maior embasamento técnico de 
programação por parte do designer.

A nova interface da edição digital da Revista Arco foi divulgada no dia 21 de agosto de 2017, com forte campanha nas redes sociais da revista. Além do visual do site ter sido modificado, novas editorias da revista foram acrescentadas para o lançamento, como o Mitômetro - um método de checagem de dados desenvolvido pela equipe do LEx -, publicações em listas e quizzes interativos.

Utilizando do Google Analytics para fazer uma comparação entre a versão antiga do website e após o lançamento da nova interface, é possível perceber o aumento no número de visualizações de página, aumento no tempo médio de permanência da página e diminuição na taxa de rejeição (Figura 12). A página com maior número de visualizações foi a reportagem especial feita para o lançamento do novo site, com um número total de 5.723 visualizações.
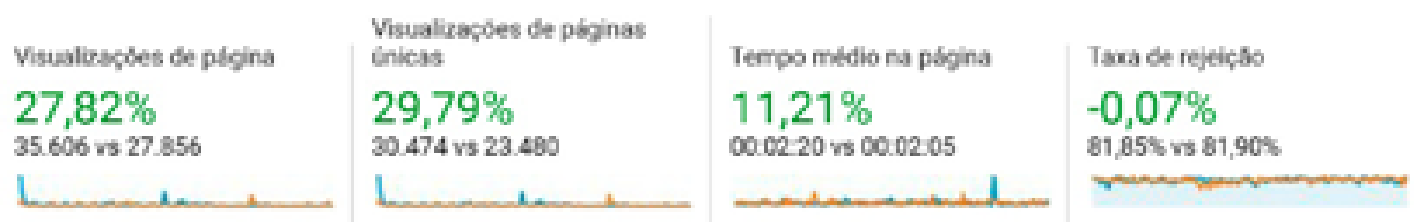

Figura 12: Dados retirados do Google Analytics com comparação entre os períodos de 20/03/17 - 20/08/17 e 21/08/17 - 21/01/18. Fonte: Google Analytics

Em termos de design, pode-se testar toda a consistência do projeto entre designers, clientes e usuário final, obtendo-se até agora resultado satisfatório, tanto no uso da metodologia, quanto nas escolhas projetuais.

\section{Considerações Finais}

O design centrado no usuário, inserindo-o no processo de projetação, demonstra maturidade no espaço do desenhista industrial. Obter feedbacks e críticas e saber lidar com elas faz parte do cotidiano desse profissional, mas, sobretudo, enriquece a interface e a experiência de usuário. O mantra de que o bom design é invisível deve ser replicado nas interfaces digitais, facilitando que o usuário possa experienciar o projeto sem percebê-lo negativamente, objetivando suas ações e oferecendo as reações corretas para o padrão mental do usuário. Simplificar os projetos em uma era de excessos informacionais pode proporcionar experiências de usuários mais agradáveis. No contexto do Projeto de Redesenho da Revista Arco, esses objetivos foram atingidos por meio de boas escolhas desenhísticas - paleta cromática, grids, tipografia, por exemplo - que foram se aperfeiçoando durante o projeto, com análises das clientes e dos usuários. Por isso, no contexto desse projeto se pode lançar a revista após com muitas interações, oriundas da inserção do usuário no processo e do apontamento de possíveis erros ou dificuldades de acesso, impactando positivamente. Essas escolhas tornaram o projeto bem-sucedido principalmente nos requisitos de legibilidade, leiturabilidade e adequação ao público da revista. A página de matéria teve uma grande aceitação por parte daqueles que a testaram, garantindo uma boa experiência de leitura. Além disso, as etapas metodológicas utilizadas, claramente 
especificadas, ordenaram e fizeram com que as várias mudanças projetuais feitas durante o processo fossem descomplicadas. Desse modo, a metodologia de projeto 5ls mostrou-se adequada e de fácil compreensão.

\section{REFERÊNCIAS}

GARRETT, Jesse James. The Elements of User Experience: User-Centered Design for the Web and Beyond. Berkley: New Riders Press, 2011

LOWDERMILK, Travis. Design Centrado no Usuário: um guia para o desenvolvimento de aplicativos amigáveis. São Paulo: Novatec Editora, 2013

NIELSEN, Jakob. The Distribution of Users' Computer Skills: Worse Than You Think. Disponível em: https://www.nngroup.com/articles/computer-skill-levels. Acesso em: 18 de mar. 2017.

TEIXEIRA, Fabrício. Introdução e Boas Práticas em UX Design. São Paulo: Casa do Código, 2014.

WROBLEWSKI, Luke. Mobile First. New York: A Book Apart, 2011. 
